\title{
HUBUNGAN POSTPARTUM BLUES DENGAN KEPUTUSAN MENGGUNAKAN KB PASCA NIFAS DI UPT PUSKESMAS LENTENG
}

\author{
Ratna Indriyani, Program Studi Diploma Kebidanan Universitas Wiraraja \\ e-mail: ratnaindriyani@wiraraja.ac.id \\ Emdat Suprayitno, Program Studi Profesi Ners Universitas Wiraraja \\ e-mail: emdats@yahoo.com
}

\begin{abstract}
ABSTRAK
Ibu nifas di UPT Puskesmas Lenteng banyak yang tidak menggunakan kontrasepsi pasca nifas dan mereka lebih memilih menggunakan metode kontrasepsi pada saat usia bayi sudah mulai berumur 2 tahun. Pengalaman dan status psikologi ibu berkontribusi besar terhadap keputusan ibu memilih metode kontrasepsi pasca persalinan.

Tujuan penelitian ini untuk menganalisa hubungan Post Partum Blues dengan Keputusan Menggunakan KB Pasca Nifas di UPT Puskesmas Lenteng. Jenis Penelitian ini yaitu analitik dengan rancangan Cross Sectional. Populasi yaitu semua ibu nifas multipara yang pernah menggunakan KB nifas di UPT Puskesmas Lenteng pada bulan Juli-Agustus tahun 2017 sebanyak 30 orang dengan total sampling. Pengumpulan data menggunakan lembar quesioner.

Hasil Penelitian didapatkan Ibu nifas yang menggunakan KB pasca nifas sebagian besar mempunyai pengalaman negatif, Ibu nifas yang kemungkinan mengalami postpartum blues sebagian besar menggunakan KB pasca nifas. Ada hubungan postpartum blues dengan keputusan menggunakan KB pasca nifas di UPT Puskesmas Lenteng tahun 2017 .
\end{abstract}

Kata Kunci : Ibu Nifas, Penggunaan KB, Post Partum Blues

\section{PENDAHULUAN}

Ibu nifas di UPT Puskesmas Lenteng banyak yang tidak menggunakan kontrasepsi pasca lahir atau nifas dan mereka lebih memilih menggunakan metode kontrasepsi setelah bayinya mulai berumur 1 tahun. Pengalaman dan status psikologi ibu berkontribusi besar terhadap keputusan dalam memilih metode kontrasepsi pasca persalinan. Pada Tanggal 29 Juni 1970 KB pertama kali ditetapkan sebagai program pemerintah dan terbentuknya Badan Koordinasi Keluarga Berencana Nasional (BKKBN)

Cara untuk menekan jumlah pertumbuhan penduduk serta kejadian AKI dan AKB dapat dilakukan dengan cara program KB. Berdasarkan data World Population Data Sheet, Indonesia menempati peringkat ke lima di dunia dengan penduduk terbanyak 249 mencapai juta. jauh diatas 9 anggota negara ASEAN (Kemenkes RI, 2014).

Berdasarkan data BKKBN, cakupan pelayanan $\mathrm{KB}$ pasca nifas sebanyak $86.455 \mathrm{ibu}$ atau $12,69 \%$ dari seluruh pengguna $\mathrm{KB}$ sebanyak 681.175 ibu. Ibu yang tidak menggunakan KB pasca nifas akan berdampak pada ketidak mampuan ibu dalam mengatur jarak kehamilan dan merawat bayi. Hal tersebut terjadi karena kehamilan dan persalinan berulang kemungkin terjadi pada ibu setelah melahirkan. Jika hal tersebut terjadi, persoalan tidak lagi hanya terkonsentrasi pada masalah kesehatan melainkan juga akan berdampak langsung pada kesejahteraan sosial dan kependudukan.

Dimana tenaga kesehatan khususnya bidan desa harus secara intensif memberikan informasi kepada ibu dengan melakukan konseling KB pasca nifas. Isi konseling yang harus disampaikan kepada ibu adalah metode $\mathrm{KB}$ yang dapat digunakan pada masa nifas dan manfaat serta efek sampingnya. Diharapkan ibu mengerti dan paham bahwa KB pasca nifas sangat penting untuk ibu dan bayi sehingga timbul perilaku postif bagi ibu untuk segera menggunakan KB setelah persalinan.

\section{BAHAN DAN CARA PENELITIAN}

Jenis penelitian yang digunakan merupakan penelitian observasional Deskriptif dengan Sampel semua ibu nifas multipara yang pernah menggunakan $\mathrm{KB}$ pasca nifas di 
UPT Puskesmas Lenteng pada bulan JuliAgustus tahun 2017 yang berjumlah 30 orang. Teknik sampling yang di gunakan adalah Total sampling. Variabel penelitian dalam penelitian ini yaitu: post partum blues dan penggunaan $\mathrm{KB}$ pasca nifas. Pengumpulan data menggunakan lembar kuesioner yang berupa cheklist, data yang terkumpul dianalisis menjadi tabel distribusi frekuensi dan dipresentasekan dari setiap variabel.

\section{HASIL PENELITIAN}

\section{Postpartum Blues}

Tabel 1. Distribusi postpartum blues di UPT Puskesmas Lenteng tahun 2017

\begin{tabular}{cccc}
\hline No & Postpartum & F & $\%$ \\
\hline 1 & Post partum blues & 16 & 53,3 \\
2 & Tidak post partum blues & 14 & 46,7 \\
\hline & Jumlah & 30 & 100
\end{tabular}

Tabel 1 menunjukkan sebagian besar responden mengalami post partum blues, yaitu sebanyak $16(53,3 \%)$ responden.

\section{Keputusan Menggunakan KB Pasca Nifas}

Tabel 2. Distribusi keputusan menggunakan KB pasca nifas di UPT Puskesmas Lenteng tahun 2017

\begin{tabular}{lccc}
\hline No & $\begin{array}{c}\text { Keputusan Menggunakan } \\
\text { KB Pasca Nifas }\end{array}$ & F & $\%$ \\
\hline 1. & Menggunakan & 13 & 43,3 \\
2. & Tidak menggunakan & 17 & 56,7 \\
\hline & Jumlah & 30 & 100 \\
\hline
\end{tabular}

Tabel 2 menunjukkan bahwa sebagian besar responden memutuskan untuk tidak menggunakan $\mathrm{KB}$ pasca nifas, yaitu sebanyak $17(56,7 \%)$ responden.

Tabel 3 Hubungan Postpartum Blues dengan Keputusan Menggunakan KB Pasca Nifas di UPT Puskesmas Lenteng Tahun 2017

\begin{tabular}{|c|c|c|c|c|c|c|c|}
\hline \multirow{3}{*}{ No. } & \multirow{3}{*}{ Postpartum Blues } & \multicolumn{6}{|c|}{ Keputusan Menggunakan KB Pasca Nifas } \\
\hline & & \multicolumn{2}{|c|}{ Menggunakan } & \multicolumn{2}{|c|}{ Tidak } & \multicolumn{2}{|c|}{ Total } \\
\hline & & $\mathrm{F}$ & $\%$ & $\mathrm{~F}$ & $\%$ & $\mathrm{~F}$ & $\%$ \\
\hline 1 & Kemungkinan & 4 & 25,0 & 12 & 75,0 & 16 & 100 \\
\hline 2 & Tidak & 9 & 64,3 & 5 & 35,7 & 14 & 100 \\
\hline \multicolumn{2}{|r|}{ Total } & 13 & 43,3 & 17 & 56,7 & 30 & 100 \\
\hline \multicolumn{8}{|c|}{ lue $=0$} \\
\hline
\end{tabular}

Tabel 3 Tabulasi silang post partum blues dengan keputusan menggunakan KB pasca nifas di UPT Puskesmas Lenteng tahun 2017

Berdasarkan tabel tabulasi diatas menunjukkan bahwa responden yang kemungkinan mengalami postpartum blues sebagian besar menggunakan KB pasca nifas, yaitu sebanyak $12 \quad(75,0 \%)$ responden. Sedangkan responden yang tidak mengalami postpartum blues sebagian besar tidak menggunakan KB pasca nifas, yaitu sebanyak $9(64,3 \%)$ responden.

Hasil analisa data dengan uji statistik inferensial menggunakan uji Chi Square diperoleh $\mathrm{P}$ value $=0,030$ dengan nilai = 0,05 , jadi $\mathrm{P}(0,030)<(0,05)$ maka $\mathrm{H} 0$ ditolak yang berarti ada hubungan post partum blues dengan keputusan menggunakan KB pasca nifas di UPT Puskesmas Lenteng tahun 2017.

\section{PEMBAHASAN}

\section{Post partum Blues}

Pada table 1 menunjukkan bahwa sebagian besar sebanyak $16 \quad(53,3 \%)$ responden kemungkinan mengalami post partum blues.

Postpartum blues, merupakan gangguan mood sementara pada hari pertama sampai hari ke 10 setelah melahirkan yang ditandai dengan perasaan kesepian, mudah lupa, letih cemas, bingung, gelisah, tangisan, tidak dapat tidur (Pillitteri, 2003). kecemasan pada responden dapat diakibatkan oleh kehamilan dan persalinan. responden menginginkan anaknya lahir dengan selamat dan sehat. Menyiapkan persalinan dengan baik dapat menambah kemampuan responden untuk melahirkan dengan kekuatannya sendiri dan tidak hanya bergantung pada proses alami persalinan. gejala psikososial dapat diakibatkan oleh proses persalinan, baik peristiwa maupun orang yang terlibat bisa 
bersifat negatif maupun positif.

Post partum blues salah satu dari reaksi psikososial yang labil dan sebagai dampak dari respon maladaptif terhadap permasalahan yang dialami responden. depresi postpartum atau psikosis postpartum dapat diakibatkan oleh postpartum blues yang tidak diatasi dengan tepat. Postpartum blues yang tidak segera diatasi dapat berdampak buruk bagi responden, bayi dan kepribadian anak.

Seseorang dengan post partum blues dapat mengalami gangguan kemampuan dalam merawat bayinya sehingga dapat merasa bersalah dan tidak percaya diri pada kemampuannya sebagai seorang ibu. Ada beberapa faktor yang secara relatif mempengaruhi postpartum blues pada responden dan dapat ditelusuri oleh peneliti. Ada beberapa faktor predisposisi yang mempengaruhi postpartum blues pada responden.

Berdasarkan umur responden menunjukkan bahwa hampir setengah umur responden adalah 27-28 tahun dan 29-30 tahun, yaitu masing-masing sebanyak 9 responden $(30,0 \%)$. Salah satu faktor pendukung terjadinya postpartum blues yaitu Kehamilan dan persalinan pada usia remaja berhubungan dengan kesiapan dalam perubahan perannya yaitu kesiapan fisik, mental, finansial dan sosial (Henshaw, 2003).

Umur responden dilihat dari perspektif fisiologi akan menimbulkan perubahan sirkulasi hormonal (progesteron dan estrogen) secara dramatis. Perubahan hormonal berpengaruh pada emosional responden. Kematangan responden juga dapat dinilai dari umur dengan indikasi kebijaksanaan dalam bersikap dan berperilaku. Kompetensi pemahaman responden merupakan bentuk kecerdasan perilaku yang disebabkan oleh karakteristik umur responden. Pemebelajaran dari sisi personal dan sosial dapat terjadi pada responden yang berumur dewasa sehingga dapat membentuk kooping adaptif dan mencegah postpartum blues.

Teori tersebut tidak berlaku pada penelitian ini. Hal ini kemungkinan disebabkan ibu yang menjadi responden adalah ibu yang paritasnya lebih dari satu (multiparitas) sehingga umur responden yang dominan adalah umur dewasa.Karakteristik responden lainnya disinyalir juga punya andil dalam menentukan angka kemungkinan post partum blues pada responden.

Berdasarkan pendidikan responden menunjukkan bahwa sebagian besar pendidikan responden adalah tamat SMA, yaitu sebanyak 17 responden $(56,7 \%)$. Cury, et al (2008) menyebutkan jika responden dengan pendidikan tingkat dasar kecenderungan mengalami maternity blues sebesar satu kali $(\mathrm{OR}=1)$. responden dengan tingkat pendidikan tinggi kecenderungan mengalami maternity blues sebesar 0,84 (OR=0,84).

Pendidikan responden merupakan suatu upaya menanamkan pengertian dan tujuan agar tumbuh pemahaman, sikap dan perbuatan positif. Pendidikan responden dapat berupa bimbingan yang muncul karena subjek dan objek terhadap perkembangan menuju arah perubahan tertentu. Peneliti hanya dapat menelusuri pendidikan formal responden.Semakin tinggi pendidikan responden semakin baik pula mekanisme kooping karena wawasan luas dapat dijadikan unsur manajemen kooping adaptif.

Berdasarkan pekerjaannya responden menunjukkan bahwa setengah pekerjaan responden adalah IRT, yaitu sebanyak 15 responden (50,0\%). Schoemaker (2005) menyatakan bahwa wanita yang memliki pekerjaan biasanya mempunyai status sosial ekonomi dan kesempatan lebih baik untuk menentukan secara otonom derajat kesehatannya. Salah satu faktor pendukung terjadinya postpartum blues adalah status sosial ekonomi (Henshaw, 2003), terkait dengan pemenuhan kebutuhan dan perawatan pada bayi menurut Cury, et. al., (2008) menjelaskan jika responden yang tidak bekerja banyak mengalami postpartum blues.

Upaya untuk menurunkan angka kemungkinan post partum blues bisa dilakukan pendidikan kesehatan pada awal kehamilan tentang perubahan fisik dan psikis pada saat hamil, persalinan, dan nifas pada saat ibu melakukan Ante ANC sekaligus dilakukan deteksi dini post partum blues. 
keterlibatan suami diperlukan dalam discharge planning dalam mendukung ibu dalam merawat bayinya. follow up dalam mencegah postpartum blues dapat dilakukan oleh bidan dengan melakukan kunjungan rumah.

\section{Keputusan Menggunakan KB Pasca Nifas}

Dalam menggunakan KB pasca nifas responden menunjukkan bahwa sebagian besar responden memutuskan untuk tidak menggunakan $\mathrm{KB}$ pasca nifas, yaitu sebanyak 17 responden $(56,7 \%)$.

Penggunaan metode KB sampai satu tahun setelah persalinan merupakan pengertian dari KB pasca nifas. tetapi, Kementerian Kesehatan membatasi periode KB setelah persalinan yaitu sampai 42 hari setelah persalinan (Mujiati, 2013).

$\mathrm{KB}$ pasca nifas merupakan deferensial dari program pelayanan KB secara umum. Program Perencanaan Persalinan dan Pencegahan Komplikasi (P4K), terdapat perencanaan penggunaan $\mathrm{KB}$ setelah nifas. Penggunaan KB pasca nifas masih belum bisa menjangkau semua sasaran yaitu ibu masa nifas.Kondisi tersebut kemungkinan terjadi karena rentang waktu pada KB pasca nifas yang dikonotasikan menjadi period/e sempit hanya selama 42 hari pasca bersalin.Pada masa nifas responden akan lebih fokus pada pemulihan kesehatan terutama kondisi fisik dan mentalnya .Responden kemungkinan juga kurang begitu peduli pada kegiatan kesehatan selain hal tersebut.

Penggunaan KB pasca nifas penting dilakukan karena kesuburan tidak dapat diprediksi . Kontrasepsi harusnya digunakan sebelum aktifitas seksual. Keuntungan yang signifikan terhadap responden dan bayinya dapat diperoleh dengan strategi Pelayanan KB pasca nifas. Pelayanan KB pasca nifas dilakukan dengan memberikan konseling dan informasi sejak masa kehamilan. Bidan sebagai pemberi pelayanan memegang peranan penting dalam memberikan informasi dan konseling KB pasca nifas kepada calon peserta KB.

Ada beberapa faktor yang secara fundamental relatif mempengaruhi keputusan responden menggunakan $\mathrm{KB}$ pasca nifas dan dapat ditelusuri oleh peneliti.Penelusuran dilakukan berdasarkan faktor predisposisi yang terdapat pada karakteristik responden. Berikut faktor predisposisi yang mempengaruhi keputusan responden menggunakan KB pasca nifas.

Dilihat dari umur responden menunjukkan bahwa hampir setengah umur responden adalah 27-28 tahun dan 29-30 tahun, yaitu masing-masing sebanyak 9 responden (30,0\%). Umur merupakan karakter mutlak yang membedakan responden karena tidak dapat dilakukan intervensi perubah dan secara alamiah mengikuti pergantian waktu. Perkembangan umur bergantung pada lama hidup responden atau konsistensinya dipengaruhi oleh proses awal dan akhir hidup responden.Ada proses penyesuaian antara umur dan pengalaman serta kesempatan belajar. Umur salah satu faktor yang menentukan perilaku responden dalam menentukanpenggunaan kontrasepsi selama nifas, semakin tua responden maka pemilihan kontrasepsike arah kontrasepsi yang mempunyai efektifitas lebih tinggi pada masa nifas yaitu KB pasca nifas.

Berdasarkan pendidikan menunjukkan bahwa sebagian besar pendidikan responden adalah tamat SMA, yaitu sebanyak 17 responden (56,7\%). Tingkat pendidikan merupakan salah satu faktor yang sangat menentukan dalam penerimaan informasi, pengetahuan, dan persepsi seseorang.

Tabel 3 menunjukkan bahwa setengah pekerjaan responden adalah IRT, yaitu sebanyak 15 (50,0\%) responden. Berdasarkan penenilitian Baroya semakin tinggi pendidikan wanita maka kesempatan berkarier semakin meningkat sehingga mengurangi minat mempunyai anak lebih banyak, sehingga lebih berpeluang mengikuti program KB pasca nifas (Baroya, 2010).

Secara teoritis disebutkan bahwa partisipasi wanita dalam angkatan kerja mempunyai pengaruh penting dalam penurunan fertilitas. Bekerja dapat mengurangi keinginan responden untuk membina keluarga besar karena dengan memiliki banyak anak jelas akan merepotkan.

Teori tersebut tidak berlaku pada penelitian ini.Hal ini disebabkan karena jumlah responden yang bekerja sebagai 
IRT lebih dominan dibandingkan pekerjaan lainnya.Perbedaan kuantitas dan karakteristik responden lainnya disinyalir punya andil dalam menentukan keputusan responden menggunakan $\mathrm{KB}$ pasca nifas.

Upaya untuk meningkatkan penggunaan $\mathrm{KB}$ pasca nifas harus diintegrasikan dalam pelayanan antenatal terpadu, kelas ibu hamil, dan P4K. bidan sebagai pemberi layanan antenatal wajib melakukan konseling KB pasca nifas kepada ibu hamil. Dalam Kelas Ibu Hamil, salah satu materi yang dibahas adalah tentang KB pasca nifas, dan dalam empat kali pertemuan, minimal satu kali pertemuan, ibu hamil didampingi oleh suami atau keluarganya. Hal ini dimaksudkan agar kesehatan ibu selama hamil, bersalin, nifas, termasuk kesehatan bayi yang baru dilahirkan dan kebutuhan akan KB pasca nifas menjadi perhatian dan tanggung jawab seluruh keluarga. Dalam P4K, ibu hamil dan keluarga diberi penjelasan tentang kesehatan maternal termasuk $\mathrm{KB}$ pasca nifas dan diminta untuk menandatangani Amanat Persalinan yang salah satunya adalah kesepakatan tentang metoda KB yang akan dipakainya kelak setelah bersalin.

\section{Hubungan Postpartum Blues dengan Keputusan Menggunakan KB Pasca Nifas di UPT Pukesmas Lenteng Tahun 2017}

Responden yang kemungkinan mengalami postpartum blues sebagian besar menggunakan $\mathrm{KB}$ pasca nifas, yaitu sebanyak $12(75,0 \%)$ responden. Sedangkan responden yang tidak mengalami postpartum blues sebagian besar tidak menggunakan KB pasca nifas, yaitu sebanyak $9(64,3 \%)$ responden. Secara deskriptif tampak ada hubungan antara postpartum blues dengan keputusan menggunakan $\mathrm{KB}$ pasca nifas di UPT Pukesmas Lenteng.

Hasil analisa data dengan uji statistik inferensial menggunakanuji Chi Square diperoleh $\rho$ value $=0,030$ dengan nilai $=$ 0,05 , jadi $\rho(0,030)<(0,05)$ maka $\mathrm{H} 0$ ditolak yang berarti ada hubungan postpartum blues dengan keputusan menggunakan $\mathrm{KB}$ pasca nifas di UPT Puskesmas Lenteng tahun 2017.
Tanda dan gejala postpartum blues yaitu tearfulness, bingung, labilitas emosi, perubahan mood dan gangguan kognitif, kurang perhatian, konsentrasi menurun (Henshaw, 2003)

Selama masa nifas responden mengalami proses adaptasi fisiologis dan psikologis. Respodenakan mempunyai tugas yang lebih berat, selain memenuhi kebutuhan dirinya, keluarga, responden juga merawat bayi yang baru dilahirkannya. Biasanya responden merasakan kelelahan, kekhawatiran atau kecemasan tentang kebutuhan perawatan diri dan bayinya. Kekhawatiran atau kecemasan yang tidak mendapatkan sistem pendukung baik akan menjadi faktor pencetus terjadinya postpartum blues. Pada masa tersebut responden dituntut untuk dapat menggunakan kooping secara efektif agar dapat mencapai respon adaptif.

Kegagalan adaptasi dari keduanya dapat menyebabkan responden berada pada rentang respon maladaptif. Responden dengan respon maladaptif memicu konsep, sikap, dan perilaku non produktif terhadap kesehatan selama nifas.Kegagalan responden dalam adaptasi psikologis juga kemungkinan memicu timbulnya postpartum blues. Responden yang mengalami postpartum blues bisa dipastikan akan mengalami penurunan konsentrasi yang berakibat pada ketidak mampuan responden dalam menerima informasi dan perlakuan. Responden terlalu fokus pada kondisi di luar perannya sebagai ibu.

Ketidak pahaman dan kurangnya perhatian responden karena postpartum blues kemungkinan akan mengakibatkan responden tidak menggunakan KB pasca nifas. sedangkan pelayanan $\mathrm{KB}$ pasca nifas bagian dari strategi penting untuk responden dan bayinya. Upaya untuk meningkatkan penggunaan $\mathrm{KB}$ pasca nifas dapat dilakukan bidan melalui eliminasi postpartum blues sebagai faktor negatif. Bidan harus mengetahui faktor penyebab postpartum blues pada ibu. Bidan harus mengetahui respon, koping dan adaptasi serta tindakan apa yang telah dilakukan oleh ibu dan keluarga dalam menghadapi masa nifas. Selain fokus pada postpartum blues, bidan juga secara konsisten memberikan informasi 
tentang penting $\mathrm{KB}$ pasca nifas untuk meningkatkan kualitas hidup ibu dan bayinya.

\section{KESIMPULAN}

1) Ibu nifas di wilayah UPT Puskesmas Lenteng tahun 2017 yang menggunakan KB pasca nifas sebagian besar mempunyai pengalaman negatif.

2) Ibu nifas di wilayah UPT Puskesmas Lenteng tahun 2017 yang kemungkinan mengalami postpartum blues sebagian besar menggunakan KB pasca nifas.

3) Ada hubungan postpartum blues dengan keputusan menggunakan KB pasca nifas di UPT Puskesmas Lenteng tahun 2017.

\section{SARAN}

Bagi profesi

Bidan harus secara intensif memberikan promosi kesehatan tentang postpartum blues dan KB pasca nifas melibatkan keluarga atau masyarakat sebagai kader penyelenggara kesehatan mandiri. Promosi kesehatan modern yang bersifat aktif dilakukan dengan cara bidan datang langsung ke rumah ibu (door to door). Pemberian asuhan kebidanan juga harus berorientasi pada prinsip etik profesi bidan dan mengesampingkan cost (biaya) jasa pelayanan.

Bagi intansi kesehatan

Instansi kesehatan harus menjadi fasilitator pendidikan yang berbasis pada pengembangan praktek dan riset. Instansi dan peneliti bekerjasama untuk memecahakan masalah kesehatan regional (kewilayahan) tentang postpartum blues dan KB pasca nifas. Pendampingan selama proses penelitian dan publikasi hasil penelitian kepada ibu dapat dilakukan institusi sebagai landasan faktual sebelum memberikan pelayanan promotif sampai rehabilitatif.

Bagi tempat penelitian

Bidan harus lebih concern terhadap masalah postpartum blues dan $\mathrm{KB}$ pasca nifas dan penyelesaiannya. Kerjasama lintas program dan sektor dengan pemanfaatan hasil penelitian dapat menjawab tuntutan pelayanan kebidanan prima terhadap keseluruhan pelayanan kesehatan di Kecamatan Lenteng. Pelatihan (kualitas) dan rekruitmen (kuantitas) bidan serta kader adalah upaya untuk meningkatkan kualitas pelayanan kebidanan. Pelatihan dilakukan pada seluruh bidan serta kader secara komperhensif, sedangkan rekrutmen dilakukan dengan memperhatikan jumlah klien dan luas wilayah untuk pemerataan jangkauan pelayanan kebidanan.

\section{DAFTAR PUSTAKA}

Arliana, W.O.D., Sarake, M., dan Seweng, A. (2012). Faktor yang berhubungan dengan Penggunaan Metode Kontrasepsi Hormonal pada Akseptor KB di Kelurahan Pasarwajo Kecamatan Pasarwajo Kabupaten Buton Sulawesi Tenggara. Makasar. Universitas Hasanudin.

Ambarwati, E.R, Diah, W. (2010). Asuhan Kebidanan Nifas. Yogyakarta: Nuha Medika.

Bahiyatun. (2009). Buku Ajar Asuhan Kebidanan Nifas Normal. Jakarta: EGC. BKKBN. (2009). Puslitbang KB dan Kesehatan Reproduksi Badan Koordinasi Keluarga Berencana Nasional. Jakarta.

BKKBN. (2014) Hasil pelaksanaan sub sistem pencataan dan pelaporan pelayanan kontrasepsi. Jakarta: Direktorat pelaporan data dan statistik.

Bobak I.M., Lowdermilk, D.L., \& Jensen, M.D., Perry, S.E. (2005). Buku Ajar Keperawatan Maternitas. Edisi 4. Alih bahasa: Maria \& Peter. Jakarta: EGC.

Curry ., Alexandre., Faisal., Menezes., Paulo., Rossi \& Tedecco., Jose., Julio. (2008). Maternity "Blues" : Prevalence and Risk Factors. The Spanish Journal of Psychology, vol 11, No.2, 593$599 . \quad$ Diunduh dari http://www.ucm.es/info/psi/docs/journ al/VII_n2_2008/art593/pdf. diakses tanggal 05 Maret 2015. 